28. Vasiliev V. V., Morozov E. V. Advanced Mechanics of Composite Materials. Elsevier, 2007. doi: https://doi.org/10.1016/b978-008-045372-9.x5000-3

29. Gaidachuk V. E., Kondratiev A. V., Chesnokov A. V. Changes in the Thermal and Dimensional Stability of the Structure of a Polymer Composite After Carbonization // Mechanics of Composite Materials. 2017. Vol. 52, Issue 6. P. 799-806. doi: https://doi.org/10.1007/s11029-017-9631-6

30. Kulaga E. S., Olenin I. G. Razrabotka golovnyh obtekateley iz kompozicionnyh materialov // Vozdushniy transport. 2006. Issue 1. P. 418-436.

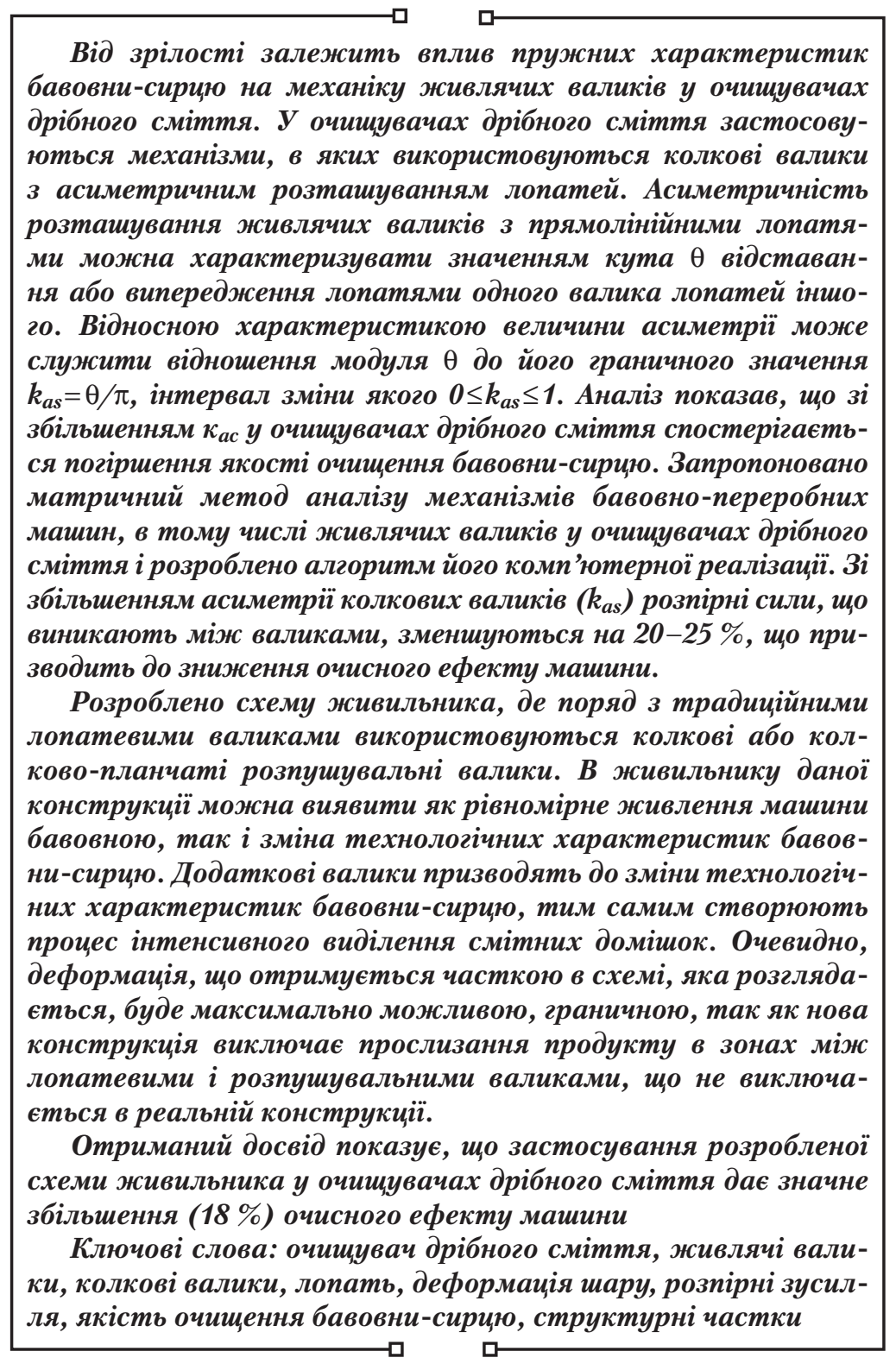

\section{INFLUENCE OF ELASTIC CHARACTERISTICS OF RAW COTTON ON THE MECHANICS OF FEED ROLLERS IN THE CLEANERS FROM SMALL IMPURITIES}

\author{
F. Veliev \\ Doctor of Technical Sciences, Professor \\ Department of technological machines \\ and equipment of the branch \\ Azerbaijan State University \\ of Economics (UNEC) \\ Istiglyaliyat str., 6, Baku, \\ Azerbaijan, AZ 1001 \\ E-mail: fazil-uzbekr@mail.ru
}

\section{Introduction}

A highly important issue for the cotton-ginning industry is to intensify the process of removing impurities from raw cotton. A high quality of cotton fiber and seeds can be achieved as a result of developing improved designs of cleaners from small impurities, finding new ways of cleaning raw cotton from small and large contaminations, and choosing modes of cleaners.
A careful study is necessary to specify the mechanics of the interaction of the working elements of the feed devices with a layer of transported material, and it is essential to search for new designs of such charging systems with a directional change in the technological properties of raw cotton.

An $80-90 \%$ increase in the cleaning effect of these technological processes allows obtaining fiber with the amount of impurities and defects within the norms. It is actually important to develop a system for assessing the uniformity of 
supply for cleaners and to determine the requirements for the characteristics of feed devices for preparing raw cotton for the main technological process. It requires creating effective cleaners for raw cotton and increasing the cleaning effect with a minimum number of cleaning machines.

\section{Literature review and problem statement}

In [1], the issues of cleaning medium-fiber raw cotton are investigated; in particular, the emphasis is placed on the strength of retaining volatiles by the roller set. A theoretical formula is proposed for calculating the efforts of separating volatiles from the blades, which has some discrepancy with the results of the experimental study. However, the effect of elastic characteristics of raw cotton is not taken into account, and in addition, the scheme does not consider the friction forces and does not take into consideration the interaction of volatiles with the asymmetrical arrangement of the blades.

In [2], tests are carried out to improve the mechanism of the feeder of spike rollers to study the interaction of a peg with a piece of raw cotton of a fibrous bond with a canvas formed by the feed rollers with a symmetrical arrangement of the blades. However, the results of the work do not show the desired cleansing effect on small impurities.

Raw cotton containing structural parts of a spherical shape with several volatile particles has been proposed to be considered in the processes occurring in the cleaners of coarse and fine contaminants [3]. Indeed, the conditions for the formation of such a cotton ball occur in the pre-cleaning section. On the basis of this model, an attempt is made to disclose the conditions for the material to be thrown onto the blade and to be fixed with a brush roller, taking into account the deformation of the raw cotton shreds. Solving the considered problems, the author reasonably focuses attention on the need for a uniform charging of the cleaners, in particular, on a largely unresolved problem of the influence of the elastic characteristics of raw cotton on the adhesion with an asymmetrical arrangement of the blades.

In [4], the question of the interaction of impurities with cotton is investigated; however, the influence of the elastic characteristics of raw cotton on the adhesion in cleaners of small admixtures with cotton is not studied.

In [5], the ways of increasing the efficiency of raw cotton cleaning from small impurities are investigated by improving planar spike rollers. However, changing the profile of the mesh surface does not improve the effect of cleaning cotton from small impurities.

In $[6,7]$, the fundamentals of the mechanics of the process of interaction of raw cotton sheaves with the working bodies of a large impurity cleaner section are given. However, the mechanics of the process of interaction of the working elements of the feed devices with the layer of the transported material are not investigated, and the search for charging systems with a directional change in the technological properties of raw cotton is not considered.

In work [8], dedicated to the choice of parameters of the geometry for the blades of the feed rollers, a process model is used that can illuminate the interaction of volatiles with the spike roller of the purifier and a number of reasons for the malformation of the process. However, there is no research on the effect of the asymmetrical arrangement of the blades on the elastic characteristics of raw cotton and, ultimately, on the quality indicators. The development of this direction can be considered in [9], in which the question of the effect of harvest time on the maturity of raw cotton is studied.

In $[10,11]$, this question is investigated only for raw cotton of machine harvesting. The authors do not consider the friction forces and the influence of the elastic characteristics of raw cotton with an asymmetrical arrangement of the blades. As a result, the desired cleaning effect is not achieved.

All this leads to a conclusion that the issues of the influence of the elastic characteristics of raw cotton on the spacer efforts, as well as ensuring the even charging of cleaners of small contaminants, remain open. Therefore, it is important to develop these studies in the part that relates to the possibility of creating a machine suitable for cleaning medium-fiber varieties with certain optimal parameters and mode of operation. Now for the cleaning of raw cotton from small impurities of medium-fiber varieties, the working section includes mainly a spike roller and a grate, which has a small cleaning effect on small impurities. This leads to a decrease in the fiber quality. When creating an appropriate design of spike rollers, the predicted increase in the cleaning effect in the technological processes can be up to $98-99 \%$. This, in turn, can help obtain fiber with the amount of impurities and defects within the regulated norm.

\section{The aim and objectives of the study}

The aims of the work are to study the process of feeding raw cotton in mechanisms of spike rollers with an asymmetrical arrangement of the blades and to determine the magnitude of the spacer forces acting on the feed rollers. This will give the opportunity to develop a new design that will allow high-quality cleaning of raw cotton from small impurities.

To achieve the aim, the following objectives were set and done:

- to identify the dynamics of the process of interaction with the raw cotton of the feed roller of the cleaner with an asymmetrical arrangement of the blades;

- to develop a new design of the mechanism for charging cotton machines, focused on changing the technological properties of raw cotton;

- to determine the methodology for assessing the utmost capabilities of the new system when deforming the structural particles of raw cotton;

- to study the process of deformation of structural particles by loosening rollers.

\section{The study of the dynamics of the process of interaction between raw cotton and a feed roller cleaner with an asymmetrical arrangement of the blades}

When the blades of rollers are asymmetrical (Fig. 1) relative to the layer of processed product $S$ at the points of contact, along with the local deformations, general movements of the layer occur, leading to a decrease in the values of the spacer efforts, and this has been largely established experimentally [10]. In the diagram, there is a general decrease in the stiffness of the deformable layer, since general deformations by the layer axis shift are added to the local contact deformations. 


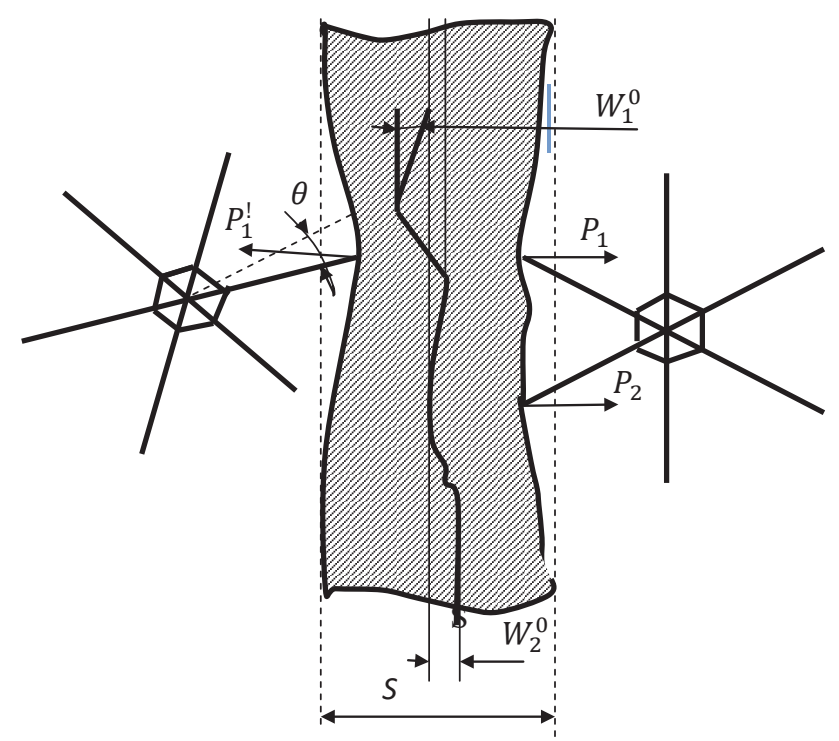

Fig. 1. A diagram of the interaction of asymmetrical feed rollers

The asymmetry of the location of the feed rollers with straight blades can be characterized by the value of the angle $\theta$ of one roller blades' lagging behind or advancing ahead of the blades of the other. It should be noted here that it is more convenient to count $\theta$ for an angle of less than or equal to half the angle between adjacent blades: $\theta \leq \pi / 2$. The relative characteristic of the value of asymmetry can be the ratio of the modulus $\theta$ to its ultimate value:

$$
k_{a s}=\frac{\theta}{\pi},
$$

and the interval of change is $0 \leq k_{a s} \leq 1$.

When $k_{a s}=0$, the case is a symmetrical arrangement of the blades; with $k_{a s}=1$, the asymmetry of the feed rollers is maximal.

When $k_{a s}>0$, the system of equations [11] is rewritten as:

$$
\left.\begin{array}{l}
W_{1}-W_{1}^{\circ}\left(P_{1}, P_{2} \ldots P_{r}\right)=W_{11}\left(P_{1}\right)+W_{12}\left(P_{2}\right)+\ldots+W_{1 r}\left(P_{r}\right), \\
W_{2}-W_{2}^{\circ}\left(P_{1}, P_{2} \ldots P_{r}\right)=W_{21}\left(P_{1}\right)+W_{22}\left(P_{2}\right)+\ldots+W_{2 r}\left(P_{r}\right), \\
------------------------------ \\
W_{r}-W_{r}^{\circ}\left(P_{1}, P_{2} \ldots P_{r}\right)=W_{r 1}\left(P_{1}\right)+W_{r 2}\left(P_{2}\right)+\ldots+W_{r r}\left(P_{r}\right),
\end{array}\right\}
$$

where $W_{r}$ denotes the total displacement of the $i$-th point of the layer.

The question of determining $W_{i}$ is an independent task related to the properties of the deformable layer. With insignificant general displacements for this purpose, the equations of the elastic line of a deformable rod can be applied, and with significant ones, the equations on a rigid thread bending can be used [12-15].

In the general case, $W_{i}^{*}$ is the function of all acting forces, which indicates the complexity of the general task, with $r \geq 3$ becoming statically indeterminable.

If it is assumed that $W_{i}^{\circ}$ is the linear function of $P_{i}$ only, the circuit analysis will be simplified. From the scheme of a two-support rigid thread, assuming that the deflection of the elastic flow axis is small, the total deflection can be determined as follows:

$$
W_{i}^{0}(P) \approx \frac{W_{i}^{0}+W_{(i+1)}^{0}}{2}+W_{i}^{0}=\frac{P_{i} t^{3}\left(2-k_{a s}\right)}{12(E J)_{y c}},
$$

where $W_{i}^{\circ}$ and $W_{(i+1)^{\prime}}^{\circ}$ are the deflections of the flow axis under the blades of the right roller; $W_{i}^{0}$ is the deflection under the blade of the left roller; $t$ is the distance between the ends of the blades of the left roller in the projection on the flow axis; $(E J)_{\text {cond }}$ is the conditional stiffness of the cotton layer for bending. When $k_{a s}=1$, (3) can acquire the sign of exact equality.

Assuming the displacement of the axis of the layer to be symmetrical, the obtained function is:

$$
W_{i}^{0}=\frac{P_{i} t^{3}\left(2-k_{a s}\right)^{2} k_{a s}^{2}}{24\left(E_{j}\right)}=\frac{P_{i} k_{a s}^{2}\left(2-k_{a s}\right)}{c}=P_{i} \lambda \geq 0,
$$

continuous, differentiable (twice); with $k_{a s}=0$, it has a minimum equal to zero, and with $k_{a s}=1$, it has a maximum equal to:

$$
W_{i \max }^{0}=\frac{P_{i} t^{3}}{24\left(E_{j}\right)_{y c}} .
$$

The condition of non-negativity of $W_{i}^{\circ}$ in (4) naturally follows from the non-negativity of $P_{i}$ for $\lambda>0$.

Taking into account (4) and $W_{i j}=\delta_{i j} P_{j}$, system (2) can be rewritten as a matrix equation:

$$
\left\|W_{j}\right\|=\left(\left\|\delta_{i j}\right\|+\lambda \cdot\|E\|\right) \cdot\left\|P_{i}\right\|,
$$

$\left\|W_{j}\right\|,\left\|\delta_{j}\right\|$ and $\left\|P_{i}\right\|$ are matrices defined by [11]; $\|E\|$ is the unit matrix $(r \times r)$.

The solution of matrix equation (6) gives the expression:

$$
\left\|P_{i}\right\|=\left(\left\|\delta_{i j}\right\|+\lambda \cdot\|E\|\right)^{-1} \cdot\left\|W_{i}\right\|,
$$

where the square matrix $\left(\left\|\delta_{i j}\right\|+\lambda \cdot\|E\|\right)^{-1}$ is the inverse matrix from $\left(\left\|\delta_{i j}\right\|+\lambda \cdot\|E\|\right)$, and their product is $\|E\|$.

For the previously considered example $(r=2)$, the following is true:

$$
\left\|P_{i}\right\|=\left\|\begin{array}{c}
P_{1} \\
P_{2}
\end{array}\right\| ; \quad\left\|W_{j}\right\|=\left\|\begin{array}{l}
W_{1} \\
W_{2}
\end{array}\right\| ; \quad\left(\left\|\delta_{i j}\right\|+\lambda\|E\|\right)=\left\|\begin{array}{l}
\delta_{11}+\lambda \delta_{12} \\
\delta_{21} \delta_{22}+\lambda
\end{array}\right\|
$$

and according to the definition of the inverse matrix and the identical equalities $\delta_{i j}=\delta_{j i}$,

$$
\left(\left\|\delta_{i j}\right\|+\lambda\|E\|\right)^{-1}=\frac{\| \begin{array}{l}
\delta_{11}+\lambda-\delta_{12} \| \\
-\delta_{12} \delta_{11}+\lambda
\end{array}}{\left(\delta_{11}+\lambda\right)^{2}-\delta_{12}^{2}} .
$$

With $W_{1}=W_{2}=45.6 \mathrm{~mm}$ and the $\Delta_{i j}$ values known from [11],

$$
P_{1}=P_{2}=\frac{45.6}{1.475 \cdot 10^{-2} k \frac{\left(2-k_{a s}\right)^{2} k_{a s}^{2}}{c}},
$$

which at $k_{a s}=0$ gives $P_{1}=P_{2}=3091.5 \frac{1}{k}$.

In the case of $r=3$, matrix equation (8) leads to a more complicated equation: 


$$
\left\|\begin{array}{l}
P_{1} \\
P_{2} \\
P_{3}
\end{array}\right\|=\frac{\left\|\begin{array}{l}
\left(\delta_{11}+\lambda\right)-\delta_{12} ; \delta_{12}\left(\delta_{13}-\delta_{11}-\lambda\right) ;-\delta_{12}-\delta_{13}\left(\delta_{11}+\lambda\right) \| \\
\delta_{12}\left(\delta_{13}-\delta_{11}-\lambda\right) ;\left(\delta_{11}+\lambda\right)^{2}-\delta_{13}^{2} \cdot \delta_{12}\left(\delta_{13}-\delta_{11}-\lambda\right) \\
\delta_{12}^{2}-\delta_{13}\left(\delta_{11}+\lambda\right) ; \delta_{12}\left(\delta_{13}-\delta_{11}-\lambda\right) ;\left(\delta_{11}+\lambda\right)^{2}-\delta_{12}^{2}
\end{array}\right\| \cdot\left\|\begin{array}{l}
W_{1} \\
W_{2} \\
W_{3}
\end{array}\right\|}{\operatorname{det}\left\|\begin{array}{l}
\left.\delta_{11}+\lambda\right) ; \delta_{12} ; \delta_{13} \\
\delta_{12} ;\left(\delta_{11}+\lambda\right) ; \delta_{12} \\
\delta_{13} ; \delta_{12} ;\left(\delta_{11}+\lambda\right)
\end{array}\right\|} .
$$

Multiplication of the matrices in the numerator of (10) with a positive determinant in the denominator gives the necessary condition for touching the top of the layer of raw cotton with the first and third blades:

$$
\frac{W_{2}}{W_{1}}=\frac{W_{2}}{W_{3}} \leq \frac{\delta_{11}+\lambda}{\delta_{12}}
$$

which for the considered example is performed when:

$$
\lambda \geq 4.57 \cdot 10^{-3} k\left[\frac{\mathrm{mm}}{\mathrm{N}}\right] .
$$

If $\lambda$ does not satisfy this condition, the calculation of the expansion force at $r=3$ reduces to the case of $r=1$, for which:

$$
P_{\max }=\frac{W_{\max }}{\delta_{11}+\lambda}=\frac{55}{9.6 \cdot 10^{-3} k+\frac{\left(2-k_{a s}\right)^{2} k_{a s}^{2}}{c}} .
$$

Table 1 shows the dependences of the values of $\lambda$ and the total spacer efforts for the considered examples at $k=23.0 \mathrm{~mm}^{2} / \mathrm{H}, \varepsilon=0.5$, and $c=108 \mathrm{~mm}$ in the function of $k_{a s}$.

Table 1

The results of calculating the spacer forces with an asymmetrical arrangement of spike rollers

\begin{tabular}{|c|c|c|c|c|c|c|}
\hline \multicolumn{7}{|c|}{$k=23.0 \mathrm{~mm}^{2} / \mathrm{H}, \varepsilon=0.5$, and $c=108 \mathrm{~mm}$} \\
\hline$k_{\text {as }}$ & 0 & 0.2 & 0.4 & 0.6 & 0.8 & 1.0 \\
\hline$P_{(N)}$ & 250 & 242 & 215 & 194 & 181 & 175 \\
\hline$P_{\Sigma}=P_{1}+P_{2(N)}$ & 270 & 260 & 254 & 224 & 218 & 210 \\
\hline$\lambda \cdot 10^{-3}(\mathrm{~mm} / \mathrm{N})$ & 0 & 1.43 & 3.75 & 6.4 & 8.54 & 9.2 \\
\hline
\end{tabular}

With an increase in the asymmetry of the spike rollers $\left(k_{a s}\right)$, the spacer forces arising between the rollers decrease by $20-25 \%$ (Table 1 ). This proves that with insignificant general displacements, the equations of the elastic line of a deformable rod can be applied, and with significant displacements, the bending equations of a rigid thread can be used.

\section{Development of a new mechanism for the design of cotton machinery, focused on changing the technological properties of raw cotton}

As shown above, the increase in the efficiency of cleaning processes is possible by directed changes in the technological properties of raw cotton: disaggregation of the structure of cotton, an increase in the total open surface of cotton par- ticles due to deformation of structural units, and a decrease in the density of its mass.

This purpose is served by the charging (feed) methods proposed in Fig. 2 and the design of the cleaner feeder, which embody the idea of connecting the charging system with the system of preparing raw cotton for cleaning processes.

The feeder diagram is shown in Fig. 2, where, along with the traditional paddle rollers 1 , loosening rollers 2 are used, both spike and spike-slatted.

Between the pairs of the rollers, a zone of directional change in the properties of raw cotton is formed - it is a fuzz of the product held by the blades of the feed rollers. Under the influence of pegs, structural particles of cotton with a large number of connected volatiles are loosened. With the pinch by one end in the feed zone, under the influence of pegs, a downsizing occurs in a rather mild mode. At the same time, for individual volatile particles and structural particles with a 2-3 volatile number, an almost unhindered passage into the machine is possible: these particles are only shaken by the pegs, fluffing and losing contact with impurities.

In the feeder of this design, both uniform feeding of the machine with cotton and a change in the technological characteristics of raw cotton are thus achieved.

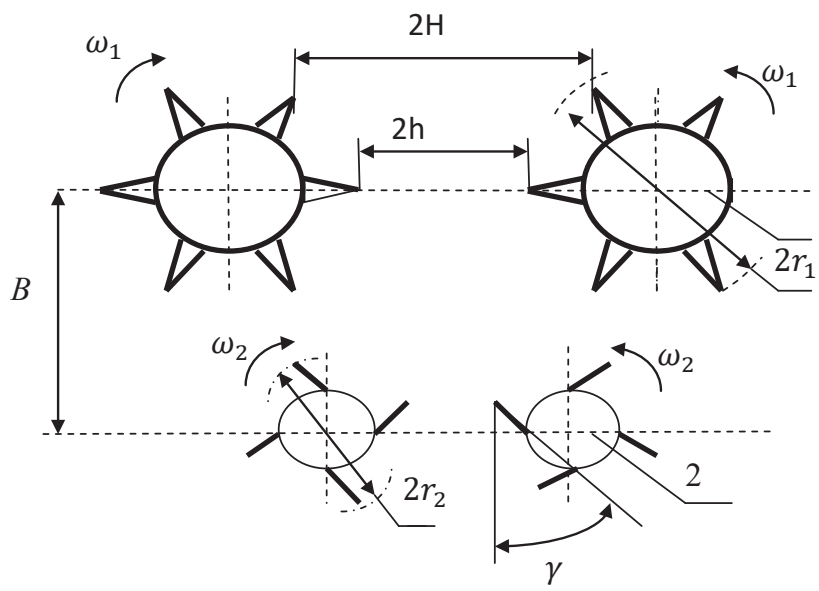

Fig. 2. A diagram of a feed device with a system for the directional measurement of the technological properties of raw cotton: 1 - bladed feed rollers; 2 - spiked loosening rollers

In the proposed design of the cleaner of small impurities, it is possible to achieve uniform charging with raw cotton and additional cleaning from small impurities. Additional rollers lead to a change in the technological characteristics of raw cotton, thereby creating a process of intensive cleansing.

6. Development of methods for assessing the utmost capabilities of the new system in the deformation of structural particles of raw cotton

Thus, it is essential to solve the general problem of estimating the ultimate possibilities of the system during the deformation of the structural particles of raw cotton.

It is assumed that the feed and spike rollers have a cylindrical shape and in the zone of the feed and exhaust steam ensure reliable pinching of the structural particle with a length (before deformation) $Z_{0}$. The radii of the feed 
rollers and their angular velocity are denoted by $r_{1}$ and $\omega_{1}$, respectively, and those for the spike rollers are denoted by $r_{2}$ and $\omega_{2}$ (Fig. 3); the length of the zone between the pinching points is marked as $B$.

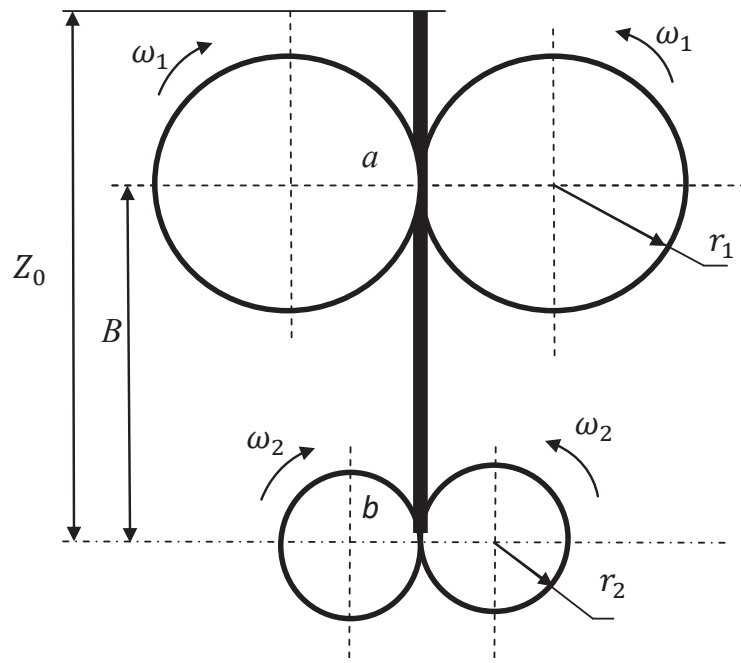

Fig. 3. A design diagram of deformation of the structural particles of raw cotton by the feed and loosening rollers

A particle, having fallen into the pinch zone $(a)$, is transported at a speed of $\omega_{1} r_{1}$ to the loosening rollers. From the moment when its lower end is in the pinch zone $(b)$, the deformation process begins, since the lower end of the particle is removed from the zone at a speed of $\omega_{2} r_{2} \gg \omega_{1} r_{1}$. The process ends when the upper end of the particle leaves the zone $a$ or the particle collapses.

Obviously, the deformation obtained by the particle in the flowchart under consideration will be maximally possible, ultimate, since the model excludes product slippage in the zones $a$ and $b$, which is not excluded in the actual design.

In the elementary period of time $d t$ after the start of the process, the elementary mass of the product is fed to the loosening zone:

$$
d m_{1}=\gamma_{x_{1}} \omega_{1} r_{1} F_{1} d t
$$

to produce:

$$
d m_{2}=\gamma_{2} \omega_{2} r_{2} F_{2} d t
$$

where, assuming a cylindrical shape of the cotton particles, $\gamma_{x_{1}}$ and $\gamma_{x_{2}}$ denote the density of raw cotton before and after deformation; $F_{1}$ and $F_{2}$ are the corresponding cross-sectional areas.

By the time a particle enters the pinch zone, there is a mass between the rollers:

$$
m_{b}=\gamma_{x_{1}} B F_{1},
$$

an elementary change of which is determined by the ratio:

$$
d m_{2}-d m_{1}=-d m_{b} .
$$

With substituting in (14) the values of (11) and (12) as well as of $d m_{b}$ in (13) and integrating, the assumption produces $\gamma_{x_{2}}(t)$ and $F_{2}(t)$ (omitting index 2 in the variables):

$$
\gamma_{x} F=\gamma_{x_{1}} F_{1}\left[\frac{\omega_{1} r_{1}}{\omega_{2} r_{2}}+\left(1-\frac{\omega_{1} r_{1}}{\omega_{2} r_{2}}\right) e^{-\frac{\omega_{2} r_{2}}{B}} t\right] .
$$

From $\gamma_{x}$ and $F$, a transition can be made to the relative deformation $\varepsilon$ of the structural raw cotton particle:

$$
\varepsilon(t)=\frac{1}{\frac{\omega_{1} r_{1}}{\omega_{2} r_{2}}+\left(1-\frac{\omega_{1} r_{1}}{\omega_{2} r_{2}}\right) \exp \left(-\frac{\omega_{2} r_{2} t}{B}\right)}-1 .
$$

At the moment of $B$ :

$$
t=\frac{Z_{0}-B}{\omega_{1} r_{1}}
$$

the relative elongation reaches a maximum:

$$
\varepsilon_{\max }=\frac{1}{\frac{\omega_{1} r_{1}}{\omega_{2} r_{2}}+\left(1-\frac{\omega_{1} r_{1}}{\omega_{2} r_{2}}\right) \cdot \exp \left[\frac{\omega_{2} r_{2}\left(B-Z_{0}\right)}{\omega_{1} r_{1} B}\right]}-1 .
$$

Obviously, the longer the structural particle, the greater the relative elongation it experiences and the more likely its destruction.

The efficiency of deformation and loosening implies that:

- firstly, the geometrical parameter of the scheme is $B$, which determines both the minimum dimensions of the non-deformable particles and the magnitude of the maximum deformation;

- secondly, the ratio of the product speeds $\omega_{1} r_{1} / \omega_{2} r_{2}$ at the points $a$ and $b$ is a kinematic parameter.

\section{Research on the process of deformation of structural particles by loosening rollers}

From the overall picture of the process, let us proceed to considering the deformation of particles of raw cotton by splitting them by the pegs of the loosening rollers.

The process diagram is shown in Fig. 4, where at the point $A$ the blades of the feed rollers pinch the raw cotton layer, and at the point $D$, which is at a distance $X$ from $A$, a peg of the loosening roller affects a structural particle of the raw cotton. For the attachment point to the angle of the splitting point to the roller with the radius $r$, the symbol $\alpha$ is assigned, and it is positive in the direction opposite to the rotation of the roller.

A cotton layer is deformed by the feed rollers from $2 \mathrm{H}$ to $2 h$, which determines the value of the arc of rotation of the feed rollers $A^{\prime} A^{\prime \prime}$, within which the fuzz of the elastic layer of raw cotton is clamped by the blades.

Since $\omega_{1} r_{1} \ll \omega_{2} r_{2}$, it is assumed that the cotton layer remains pinched during the entire impact of the spikes on the fuzz, and the case when, in the process of deforming, the blades release the fuzz at the point $A$ and it gets pinched by the next pair of blades is not considered because of the small specific weight.

$\Delta$ is used to denote half of the segment $A^{\prime} A^{\prime \prime}$, and it is determined from the geometric ratio (Fig. 5):

$$
\Delta=\frac{A^{\prime} A^{\prime \prime}}{2}=\sqrt{r_{1}^{2}+\left(r_{2}-H+h\right)^{2}} .
$$


The process of a peg interacting with a raw cotton layer can be divided into three main phases. The first is the introduction of the peg of the loosening roller into the cotton layer from the moment it touches it to the termination of the relative sliding of the fibrous material along the surface of the peg.

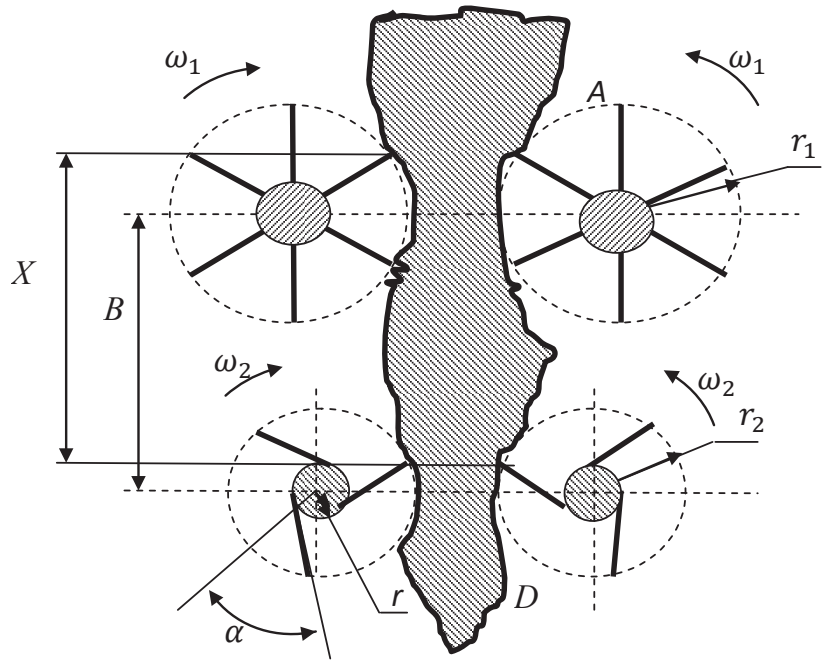

Fig. 4. A general diagram for calculating the deformation of structural particles of raw cotton between the feed and spike pairs

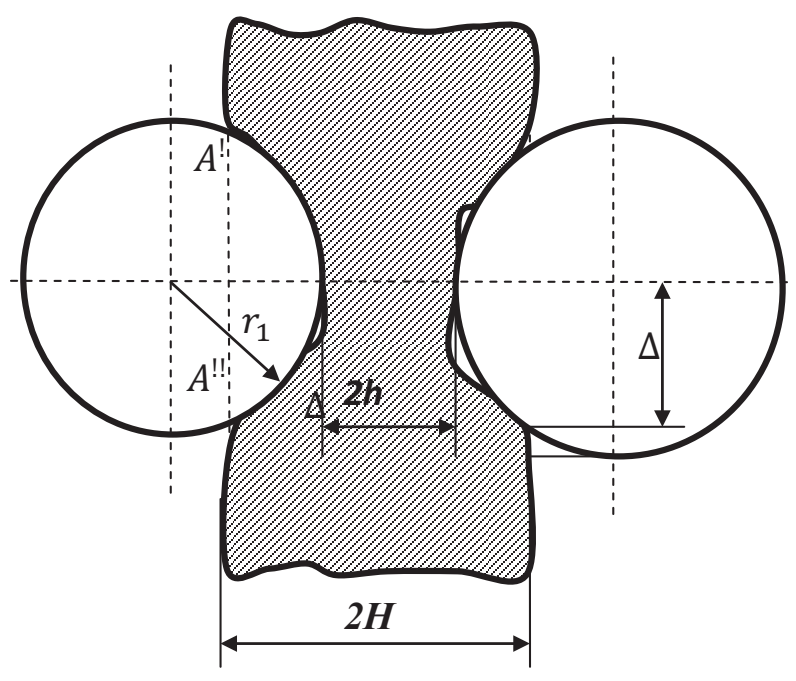

Fig. 5. A diagram for calculating the zone of a raw cotton layer pinching by the blades

The moment of the contact (Fig. 6) is determined by the ratio:

$$
\Delta_{1}=-r_{2} \cos \gamma_{0}=-\sqrt{r^{2}-(H-h)^{2}} .
$$

The moment of the stop of the cotton slipping on the surface of the peg occurs due to friction. If Amonton's friction law is taken into account, then the slip will stop at the angle between the direction of movement and the axis of the peg:

$$
\lambda_{c}=\frac{\pi}{2}-\rho=\gamma+\varphi
$$

where $\rho$ is the friction angle; $\varphi$ is the angle of rotation from the moment of touching to the termination of sliding; $\gamma=\gamma_{1}-\alpha_{1}$ is the angle between the peg and the cotton flow axis at the moment of contact; $\alpha_{1}$ is the angle between the axis of the peg and the straight line connecting the end of the peg with the axis of the roller.

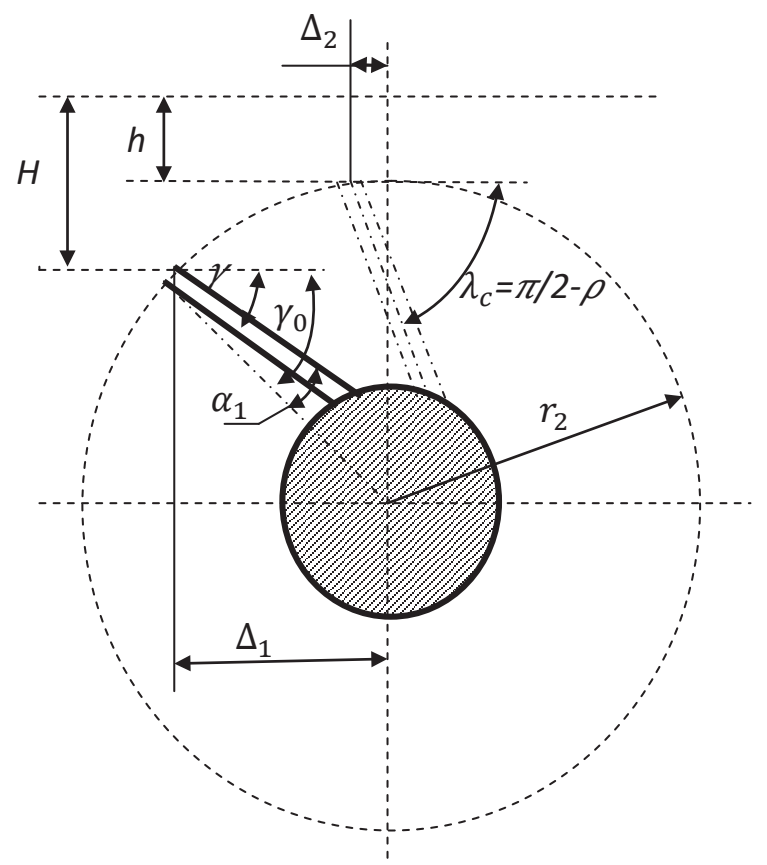

Fig. 6. A diagram to determine the moment when a peg touches a layer of raw cotton and to show the conditions for stopping the sliding of the fibrous material on the surface of the peg

The moment of the stop of the cotton slipping corresponds to the segment $\Delta_{2}$ :

$$
\Delta_{2}=r_{2} \sin \left(\alpha_{1}-\rho\right)
$$

Expression (20) can be derived from the equilibrium condition of the cotton particle on the surface of the peg under the action of a force $T$ parallel to the direction of motion. Indeed, with projecting $T$ onto the peg axis and an axis perpendicular to it produces (Fig. 7), the result is:

$$
\frac{\pi}{2}+\rho \geq \lambda_{c} \geq \frac{\pi}{2}-\rho
$$

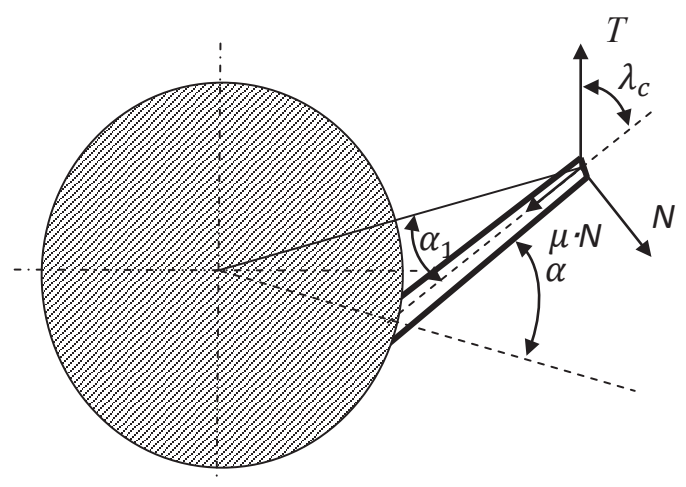

Fig. 7. Conditions of equilibrium of the cotton element on the surface of the peg 
This phase of the movement is accompanied by some deformation of cotton particles, which can be neglected in the first approximation.

The second phase is the deformation of the cotton raw layer with relative rest of the clamped cotton particles and the spike surface. Conditions (22) correspond to this zone, and the maximum displacement of the pinch point is determined as follows:

$$
\Delta_{3}=r_{2} \sin \left(\alpha_{1}+\rho\right) .
$$

With a total initial length of the deformable particle $X$ to the beginning of this phase of the process:

$$
X=B \pm \sqrt{r_{1}^{2}+\left(r_{1}-H+h\right)^{2}}+r_{2} \sin \left(\alpha_{1}-\rho\right)
$$

and the maximum value of the absolute deformation, reducible to the form, taking into account with some approximation the movement of the blades of the feed rollers during the rotation of the spike roller at an angle of $2 \rho$ :

$$
\Delta X_{2 \max }=2\left(r_{2} \sin \rho \cdot \cos \alpha_{1}-\rho r_{1} \frac{\omega_{1}}{\omega_{2}}\right),
$$

it is easy to determine the maximum value of the relative strain in this phase of the process:

$$
\varepsilon_{2 \max }=\frac{2\left(r_{2} \sin \rho \cdot \cos \alpha_{1}-\rho r_{1} \frac{\omega_{1}}{\omega_{2}}\right)}{B-\sqrt{r_{1}^{2}+\left(r_{1}-H+h\right)^{2}}+r_{2} \sin \left(\alpha_{1}-\rho\right)} .
$$

If we take into account that any previous blade goes before each blade considered, the maximum value of the initial length of $X$ will be somewhat different, determined from the relation:

$$
X_{\max }=B+r_{1} \sin \left(\arccos \frac{r_{1}-H+h}{r_{1}}-\frac{2 \pi}{n}\right)+r_{2} \sin \left(\alpha_{1}-\rho\right) .
$$

In this case, indeed, it is necessary to meet the condition that:

$$
X_{\max } \geq L_{0} .
$$

In order to avoid the formation of nodules on the spike rollers, it is desirable to complete the process of destroying structural particles in this phase, for which, in (26), $\varepsilon_{\max }$ should exceed the relative deformation of cotton particles when they are broken down as $\varepsilon_{x}$.

The third phase of the process is the contraction of the particles caught by a peg to its base. It occurs when condition (22) is violated on the left. Considering that $\lambda_{c}=\gamma+\varphi(t)$, the result is:

$$
\Delta X_{3}=-k r_{2}\left[\cos \left(\alpha_{1}+\gamma+\varphi\right)+\sin \left(\rho+\alpha_{1}\right)\right]-r_{1} \varphi \frac{\omega_{1}}{\omega_{2}} .
$$

By analogy, the relative deformation value can be obtained:

$$
\varepsilon_{3}=\frac{\Delta X_{3}}{X}
$$

The total deformation in the second and third phases of the splitting interaction with raw cotton will be:

$$
\varepsilon=\varepsilon_{2 \max }+\varepsilon_{3} \geq \varepsilon_{x} .
$$

The coefficient $k<1$ accounts for the shift of the point of picking cotton particles to the base of the peg.

\section{Discussion of the results of studying the effect of the elastic characteristics of raw cotton on the mechanics of the feed rollers in cleaners from small impurities}

As a result of the research, interactions of small impurities with fiber have been determined. For the proposed charging system, the ultimate problem of deforming structural cotton particles has been solved; the optimal wiring values, inclination angles of the pegs of the loosening rollers in the processes of introduction, capture, deformation and self-resetting have been determined by calculation. The design of the feed device, which was developed and tested in the laboratory of the mechanics of cotton machines, has the following parameters: $r_{1}=70 ; r_{2}=45 ; B=120 ; 2 h=60$ (all dimensions are in $\mathrm{mm}) ; n=6 ; \alpha=\pi / 6$. The calculated initial length $X$ of an element with $\mu=0.35-0.48(\rho=0.337-0.447)$ and a thickness of $2 H=140$ was determined by the range from $X_{\min }=48-53$ to $X_{\max }=118-123$ with an average $X_{a v}=83-88$.

The analysis of the structural composition of raw cotton passing through the feed device under consideration has shown that particles with eight or more volatiles, whose dimensions are $L_{0}=100-140 \mathrm{~mm}$, are almost completely disaggregated. The relative deformation of these particles reaches $\varepsilon_{2}=0.346-0.851$ with $\mu=0.48$ and $\varepsilon_{2}=0.243-0.563$ with $\mu=0.35$.

If the deformation in the third phase of the process is also taken into account, then the total elongation for the listed friction coefficients at $k=0.5$ and $j=0.175$ will be $\varepsilon=0.526-1.293$ and $\varepsilon \geq 0.438-1.015$, respectively.

It is noteworthy that for the equations of the ultimate process problems (16) and (17) with $\omega_{2} r_{2} / \omega_{1} r_{1}=5.71$, $Z_{0}=130$ and $Z_{0}=140 \mathrm{~mm}$, there is the deformation $\varepsilon_{\max }$, equal to 5.59 and 18.2 , respectively.

The advantages of this study in comparison with analogues can be the fact that in order to improve existing structures and enhance the cleaning effect (18\%), a number of highly efficient designs of the feed roller blades were developed, allowing to preserve the natural qualities of cotton and its seeds as much as possible. In the existing scheme of interaction of the feed rollers, in which at $k_{a s}=1$ the dependences of the values of $\lambda$ and total spacer forces are specified, for the considered examples $\lambda \cdot 10^{-3}(\mathrm{~mm} / \mathrm{N})$ decreases by $25 \%$. The flowchart of the feeder of the new design provides, along with the traditional paddle rollers, for the use of loosening rollers, spike and spike-slatted. Typically, under the influence of pegs, structural particles of cotton with a large number of connected volatiles are loosened so that the particles are only shaken with pegs, fluffing out and losing contact with impurities. In this design, both the uniform feeding of the machine with cotton and the change in the technological characteristics of raw cotton are achieved.

With an increase in $\omega_{2} r_{2} \gg \omega_{1} r_{1}$, the cotton layer remains pinched during the entire time that the spikes impact raw cotton particles between the feed rollers, which increases the fiber damage by $0.25 \%$. 
In order to avoid the process of damage to the fibers on the rollers, it is desirable to carry out the process of destruction of the structural particles with the ratio of product speeds of $\omega_{1} r_{1} / \omega_{2} r_{2} \leq 5.71$.

\section{Conclusion}

1. The study has revealed the mechanics of the process of interaction of the feed roller blades with the transported layer of raw cotton. The geometric problem of deforming the layer by paddle rollers is solved, and the extremes of the total deformation are analytically determined. With $\omega_{2} r_{2} / \omega_{1} r_{1}=5.71$, when $Z_{0}=130$ and $Z_{0}=140 \mathrm{~mm}$, there is the deformation $\varepsilon_{\max }$, equal to 5.59 and 18.2 , respectively. The matrix method was used for calculating the spacers and the shape of the deformable layer, based on the system of elastic characteristics of raw cotton.

2. One of the results is the comprehensive analysis of the feed system with an asymmetrical arrangement of the blades of the feed rollers; the power consumption of the feed rollers has been evaluated, and the positions of the stable and unstable equilibriums of the rollers have been determined (Table 1 ).
The forces acting on the feed rollers with $k_{a s}=0$ and $P=250 \mathrm{H}$ are $P_{\Sigma}=P_{1}+P_{2}=270 \mathrm{H}$, and with $k_{a s}=1$ and $P=175$, they are $P_{\Sigma}=P_{1}+P_{2}=210 \mathrm{H}$.

3. The study has suggested the principles of designing a charging system with elements of preparing raw cotton for cleaning processes, focused on changing the technological properties of cotton. The relative deformation of raw cotton reaches $\varepsilon_{2}=0.346-0.851$ with $\mu=0.48$ and $\varepsilon_{2}=0.243-0.563$ with $\mu=0.35$.

4. For the proposed feed system, the ultimate problem of deforming structural cotton particles has been solved; the optimal wiring values, the tilt angles of the pegs of the loosening rollers in the processes of introduction, capture, deformation and self-resetting have been determined by calculation. The necessary conditions for touching the surface of a cotton raw layer with the first and third blades have been obtained. It has been shown that with an increase in the asymmetry of the spike rollers, the spacer forces arising between the rollers decrease by $20-25 \%$. This proves that with insignificant general displacements, the equations of the elastic line of a deformable rod can be applied, and with significant displacements, the equations of bending of a rigid thread can be used.

References

1. Sapon A. L., Samandarov S. A., Libster S. L. Potochnaya liniya pervichnoy pererabotki hlopka-syrca PLPH // Hlopkovaya promyshlennost'. 1977. Issue 3. P. 1-3.

2. Nesterov G. P., Borodin P. N., Belyalov R. F. Novaya potochnaya liniya sushki i ochistki hlopka-syrca // Hlopkovaya promyshlennost'. 1978. Issue I. P. 2-4.

3. Tyutin P. N., Lugachev L. E. O vydelenii sornyh primesey cherez yacheyki setchatyh poverhnostey // Mekhanicheskaya tekhnologiya voloknistyh materialov. 1977. Issue 19. P. 51-58.

4. Hafizov I. K., Rasulov A. Issledovanie razryhlitel'nogo effekta razdelitelya dolek tonkovoloknistogo hlopka-syrca na letuchki // Hlopkovaya promyshlennost'. 2009. Issue 3. P. 9.

5. Miroshnichenko G. I., Burnashev R. Z. Optimizaciya konstruktivnyh parametrov kolosnikovo-pil'chatyh rabochih organov i sistem pitaniya ochistiteley krupnogo sora. Otchet po teme 3/I-74-2I. Tashkent, 1999. 259 p.

6. Baydyuk P. V. Primenenie valkovyh ustroystv pri pressovanii voloknistyh materialov // CINTI. 1964. Issue 4. P. 2-8.

7. Miroshnichenko G. I., Burnashev R. Z. Vybor parametrov ustroystv dlya izmeneniya napravleniya dvizheniya semyan // Hlopkovaya promyshlennost'. 1973. Issue 3. P. 20

8. Boldinskiy G. I., Maksudov H. T. O rabote otboynyh ustroystv, primenyaemyh na daynah dlya povysheniya stepeni ochistki volokna ot sornyh primesey // Hlopkovaya promyshlennost'. 1972. Issue 1.

9. Sailov R. A., Veliev F. A., Kerimov Q. K. Research into the process of mechanical formation of the upper part of a raw cotton bundle // Eastern-European Journal of Enterprise Technologies. 2017. Vol. 4, Issue 1 (88). P. 56-63. doi: https://doi.org/10.15587/ 1729-4061.2017.108948

10. Influence of storage duration and density of raw cotton on the mechanics of the interaction process between feeding rollers in the cleaners of large impurities / Veliev F., Sailov R., Kerimova N., Safarova T., İsmailzade M., Sultanov E. // Eastern-European Journal of Enterprise Technologies. 2018. Vol. 3, Issue 1 (93). P. 78-83. doi: https://doi.org/10.15587/1729-4061.2018.132493

11. Veliev F., Sailov R. Influence of elastic characteristics of raw cotton on the mechanics of feed rollers in the cleaners from large impurities // Eastern-European Journal of Enterprise Technologies. 2018. Vol. 5, Issue 1 (95). P. 53-60. doi: https://doi.org/ 10.15587/1729-4061.2018.143133

12. Fedos'ev V. I. Soprotivlenie materialov. Moscow: «Nauka», 1994. 560 p.

13. Osnovy mekhaniki niti / Yakubovskiy Yu. V., Zhivov B. C., Koritysskiy Ya. I., Migushov I. I. Moscow: «Legkaya industriya», 1973. $271 \mathrm{p}$.

14. Timoshenko S. P., Gud'er D. Teoriya uprugosti. Moscow: «Nauka», 1975. 576 p.

15. Samandarov S. A. Nekotorye elementy teorii ochistki hlopka // Sbornik nauchno-issledovatel'skih rabot CNIIHproma. 1958. Issue 1U. P. 9-11. 